\title{
Uterine Cervical Involvement of Non-Hodgkin Lymphoma; Rare Cause of Postcoital Bleeding
}

Ozer Birge ${ }^{1}$, mehmet bakır ${ }^{2}$, Ceyda Karadağ ${ }^{2}$, can dinc $^{3}$, ahmet boduroglu ${ }^{4}$, and tayup simsek $^{4}$

${ }^{1}$ Sudan Nyala-Turkey Hospital

${ }^{2}$ Affiliation not available

${ }^{3}$ Akdeniz Universitesi

${ }^{4}$ Akdeniz University Medical School

October 22, 2020

\begin{abstract}
Non-Hodgkin's lymphoma of the female genital system is extremely rare. It may be confused with cervix uteri malignancies when being diagnosed.
\end{abstract}

\section{Hosted file}

main_manuscript (1).pdf available at https://authorea.com/users/337482/articles/488233uterine-cervical-involvement-of-non-hodgkin-lymphoma-rare-cause-of-postcoital-bleeding

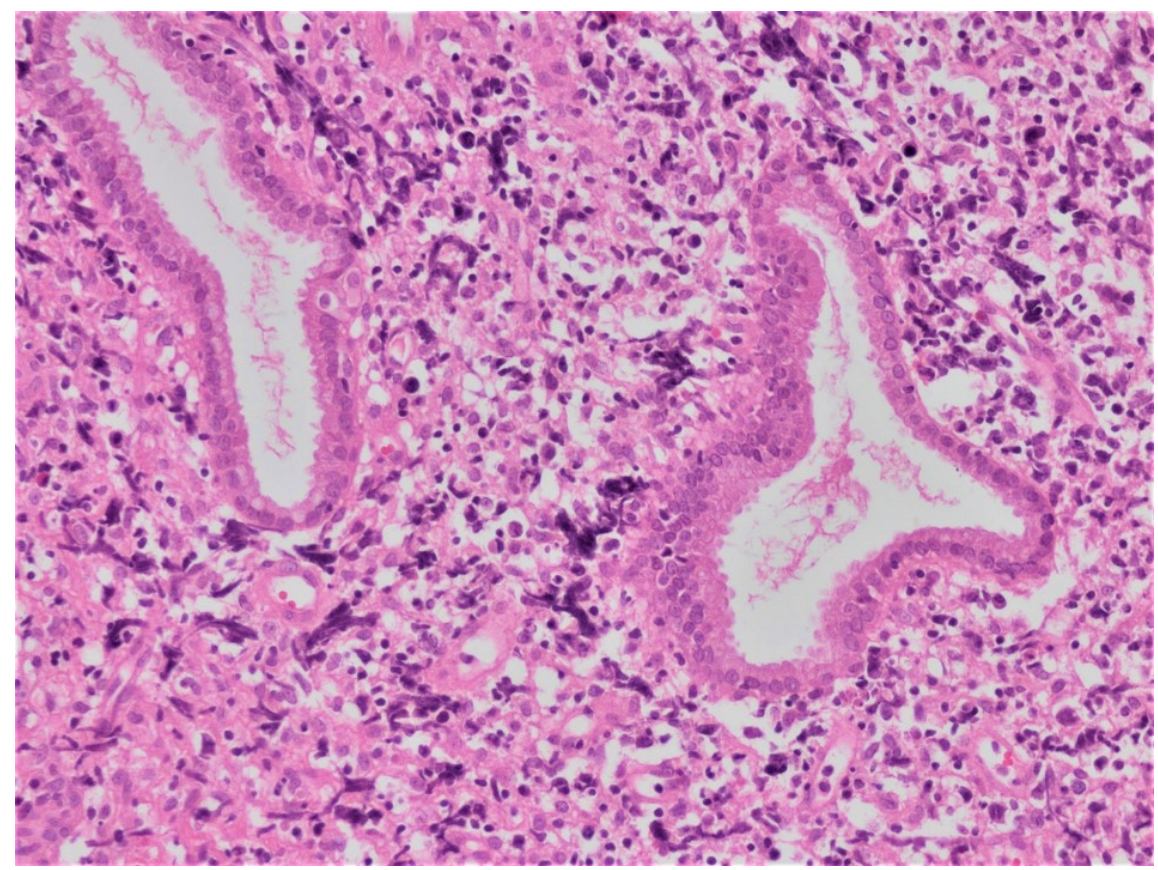




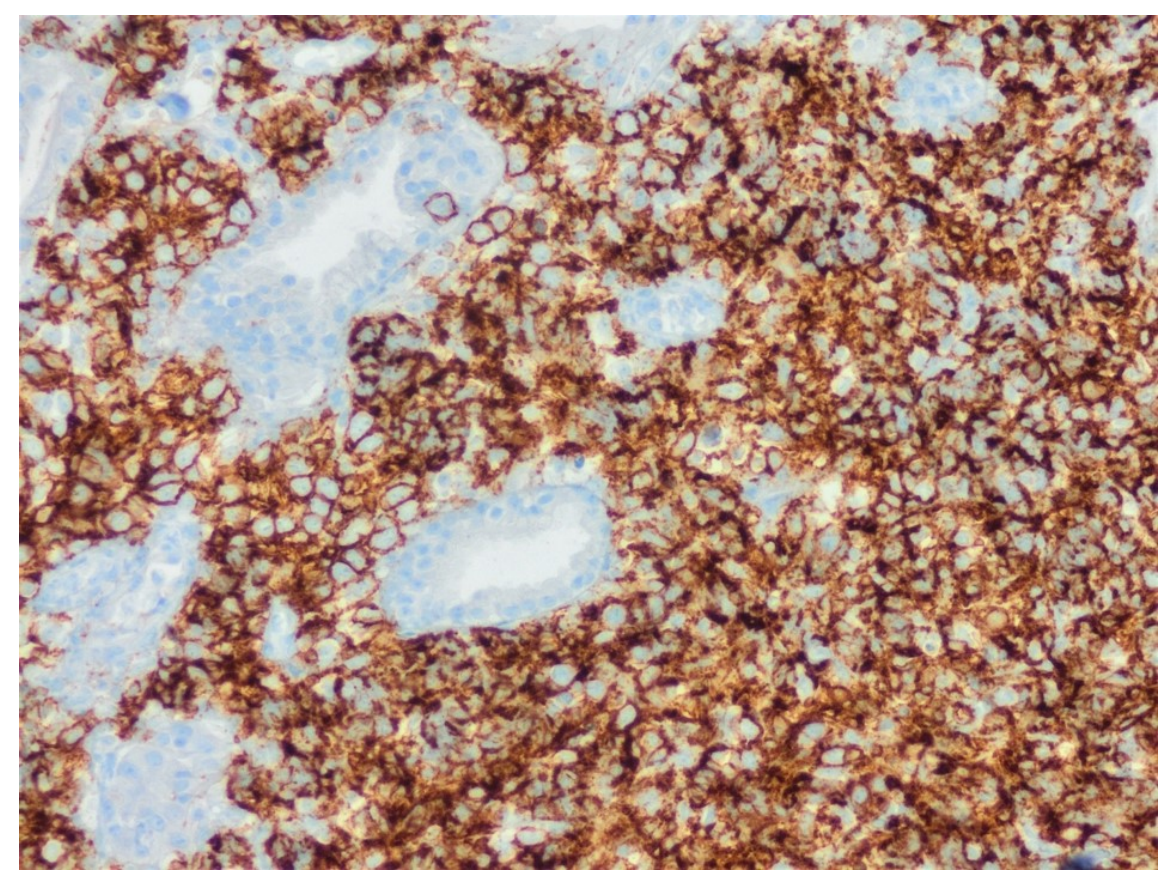

